\title{
Macroeconomic Uncertainty Through the Lens of Professional Forecasters
}

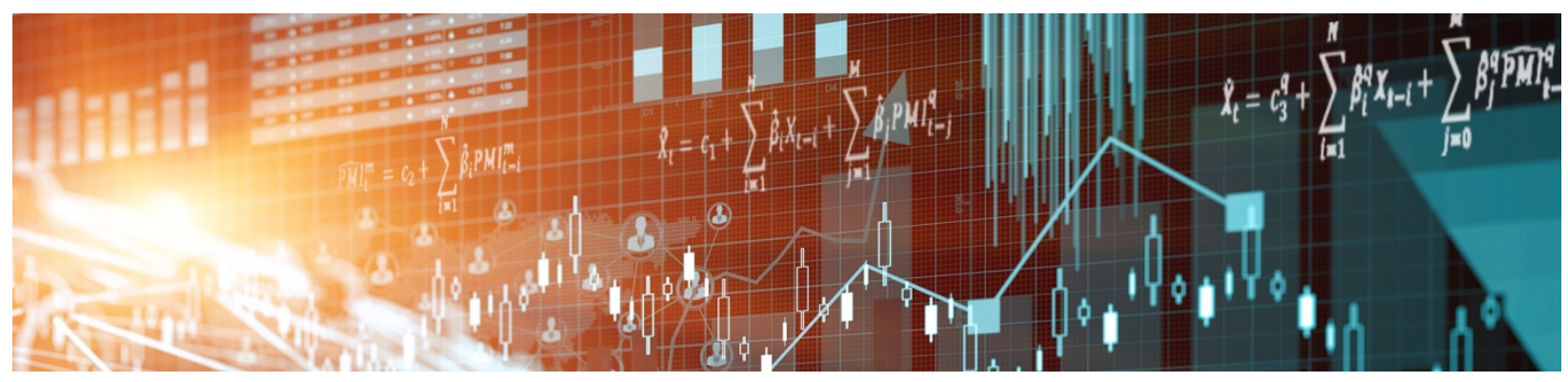

by Soojin Jo and Rodrigo Sekkel 
Bank of Canada Staff Working Paper 2016-5

February 2016

\title{
Macroeconomic Uncertainty Through the Lens of Professional Forecasters
}

\author{
by
}

\author{
Soojin $\mathrm{Jo}^{1}$ and Rodrigo Sekkel ${ }^{2}$ \\ ${ }^{1}$ Canadian Economic Analysis Department \\ Bank of Canada \\ Ottawa, Ontario, Canada K1A 0G9 \\ sjo@bankofcanada.ca \\ ${ }^{2}$ Financial Markets Department \\ Bank of Canada \\ Ottawa, Ontario, Canada K1A 0G9 \\ rsekkel@bankofcanada.ca
}




\section{Acknowledgements}

We thank Natsuki Arai, Greg Bauer, Christiane Baumeister, Marcelle Chauvet, Peter Christoffersen, Rafaella Giacomini, Lutz Kilian, James D. Hamilton, Monica Jain, Alejandro Justiniano, Kajal Lahiri, Michael McCracken, Ulrich Mueller, Xuguang Sheng, Gregor Smith, and Alexander Ueberfeldt for useful comments and suggestions, as well as seminar participants at American University, the Bank of Canada, U.S. Bureau of Economic Analysis, Hamilton College, SUNY Albany, University of Alberta, the 2014 Workshop on Uncertainty and Economic Forecasting (UCL), 2014 Canadian Economic Association, 2014 Computing in Economics and Finance, 2014 IAAE meetings, and the 2014 Society for Economic Measurement meeting, the 2015 CIRANO Real-Time Workshop, and the St. Louis Fed Applied Time Series Econometrics Workshop. 


\begin{abstract}
We analyze the evolution of macroeconomic uncertainty in the United States, based on the forecast errors of consensus survey forecasts of different economic indicators. Comprehensive information contained in the survey forecasts enables us to capture a realtime subjective measure of uncertainty in a simple framework. We jointly model and estimate macroeconomic (common) and indicator-specific uncertainties of four indicators, using a factor stochastic volatility model. Our macroeconomic uncertainty has three major spikes, aligned with the 1973-75, 1980, and 2007-09 recessions, while other recessions were characterized by increases in indicator-specific uncertainties. We also demonstrate for the first time in the literature that the selection of data vintages substantially affects the relative size of jumps in estimated uncertainty series. Finally, our macroeconomic uncertainty has a persistent negative impact on real economic activity, rather than producing "wait-and-see” dynamics.
\end{abstract}

JEL classification: C38, E17, E32

Bank classification: Business fluctuations and cycles; Econometric and statistical methods

\title{
Résumé
}

Nous analysons l'évolution de l'incertitude macroéconomique aux États-Unis, à partir des erreurs de projection de différents indicateurs économiques. Celles-ci donnent des renseignements détaillés qui nous permettent de dégager une mesure subjective en temps réel de l'incertitude dans un cadre de référence simple. Nous avons à la fois modélisé et évalué l'incertitude macroéconomique (commune) et l'incertitude propre à quatre indicateurs, à l'aide d'un modèle factoriel à volatilité stochastique. D'après notre analyse, l'incertitude macroéconomique connaît trois pics principaux, qui coïncident avec les récessions de 1973-1975, de 1980 et de 2007-2009. Les autres récessions se caractérisent par une hausse de l'incertitude inhérente à chacun des indicateurs. Pour la première fois dans la littérature, nous démontrons également que le choix de la cuvée de données influe considérablement sur l'importance relative des sauts dans la série d'incertitudes évaluées. En dernier lieu, loin d'instaurer une dynamique attentiste, l'incertitude macroéconomique observée a une incidence défavorable persistante sur l'activité économique réelle.

Classification JEL : C38, E17, E32

Classification de la Banque : Cycles et fluctuations économiques; Méthodes économétriques et statistiques 


\section{Non-Technical Summary}

This paper analyzes the evolution of macroeconomic uncertainty in the United States by using consensus survey forecasts to estimate a subjective measure of uncertainty. Survey forecasts are not tied to any particular econometric model and have often been found to be more accurate than those forecasts based on the econometric models, especially for short horizons. We apply a factor stochastic volatility model to forecast errors of a set of economic indicators from the Survey of Professional Forecasters conducted by the Federal Reserve Bank of Philadelphia. Our parsimonious framework jointly models the common (macroeconomic) and indicator-specific uncertainties in one step.

Our estimated macroeconomic uncertainty is significantly more persistent than traditional proxies of uncertainty, with all major spikes associated with deep economic recessions (i.e., the 1973-75, 1980 and 2007-09 recessions). However, other recessions (i.e., the 1990-91 and 2001 recessions) are still notable in the dynamics of some of the idiosyncratic uncertainties.

In addition, a vector autoregression (VAR) analysis shows that positive innovations to macroeconomic uncertainty are associated with decreases in a variety of real economic variables; investment, non-durable and durable consumption, and GDP all decline after an increase in macroeconomic uncertainty. The impact of uncertainty shocks is not only sizable but also highly persistent. We do not find any evidence supporting subsequent overshooting in economic activity as the uncertainty shock dissipates. This contrasts with the findings from previous VAR analyses using traditional proxies for macroeconomic uncertainty, such as the VIX.

We also examine the impact of data revisions on the estimation of economic uncertainty. We find large differences in the relative size of jumps in uncertainty series depending on the specific vintage of the data. Hence, a data vintage selection can be very important, especially when the interest lies in estimating the relative level of macroeconomic uncertainty over time. To the best of our knowledge, our paper is the first study to document the importance of data revision to the estimation of uncertainty. Together, our findings deepen our understanding of the evolution of macroeconomic uncertainty and its relation to the macroeconomy. 


\section{Introduction}

The literature on the impacts of uncertainty on real economic activity has recently witnessed a rapid growth following the Great Recession. ${ }^{1}$ Many studies have aimed at empirically quantifying the effect of uncertainty. Central to these studies is a need for a measure of time-varying uncertainty, since uncertainty is not directly observable. Accordingly, a number of proxies for uncertainty have been used. Bloom (2009) has pioneered the use of the VIX, the implied stock market volatility based on the S\&P index. Alternatively, Bloom et al. (2012) use the cross-sectional dispersion of total factor productivity shocks. Another popular proxy is the cross-sectional disagreement of individual forecasts, as in Bachmann et al. (2013). A proxy constructed using word searches from newspaper articles is proposed in Alexopoulos and Cohen (2009). Finally, the Baker et al. (2013) Economic Policy Uncertainty index combines news article counts with the number of federal tax code provisions set to expire as well as the forecast disagreement.

This paper analyzes the evolution of macroeconomic uncertainty in the United States by using consensus survey forecasts for the estimation of a subjective measure of uncertainty. In particular, we use the median forecasts of four economic indicators from the Survey of Professional Forecasters (SPF) conducted by the Federal Reserve Bank of Philadelphia. Using survey forecasts provides the following advantages. First, they are not tied to any particular econometric models. This implies that the selection and estimation of a specific forecasting model to obtain forecast errors are not necessary, and hence the overall uncertainty estimation procedure is simplified to a great extent. Second, subjective forecasts have often been found to be more accurate than forecasts from econometric models. ${ }^{2}$ Professional forecasters base their forecasts on various econometric models, leading indicators and surveys, as well as a large number of available macroeconomic and financial data, encompassing information from a wide range of sources (see Zarnowitz and Braun 1993). Therefore, survey forecasts provide an effective way of removing expected variation

\footnotetext{
${ }^{1}$ See, for example, Bloom (2009), Arellano et al. (2012), Caggiano et al. (2014), Aastveit et al. (2013), and Mumtaz and Surico (2013), among many others.

${ }^{2}$ For example, Ang et al. (2007) and Faust and Wright (2013) document the advantage of surveys over forecasting models for inflation. Aiolfi et al. (2011) study the optimal combination of the two types of forecasts for different indicators, and find that combinations always improve over time-series models, but still fail to systematically improve on the survey forecasts alone.
} 
in macroeconomic series. As highlighted by Jurado et al. (2015), it is crucial to remove the predictable component of macro series when estimating macroeconomic uncertainty so as not to attribute some of the predictable variability to unpredictable shocks.

Based on various economic indicators from the SPF, we define macroeconomic uncertainty as the conditional time-varying standard deviation of a factor that is common to forecast errors for four macroeconomic indicators such as gross domestic product, unemployment, industrial production and housing starts. In other words, an increase in macroeconomic uncertainty implies a higher probability that such economic variables simultaneously deviate from their conditional survey forecasts. This idea is effectively captured by a factor stochastic volatility (FSV) model, first developed by Pitt and Shephard (1999). The stochastic volatility process has been widely adopted in finance literature. ${ }^{3}$ More recently, it has been also often employed in macroeconomic analysis to model the time-varying volatility of macroeconomic variables. ${ }^{4}$ In our application, we use stochastic volatility processes in a factor model structure to provide both time-varying common (macroeconomic) and indicator-specific uncertainty indexes. The indexes are jointly modeled and consistently estimated in one step.

Our estimated macroeconomic uncertainty is significantly more persistent than traditional proxies of uncertainty (e.g., the VIX). In particular, all major spikes of uncertainty are associated with episodes of economic recessions, i.e., the 1973-75, 1980, and 2007-09 recessions, similar to the findings in Jurado et al. (2015). However, other recessions (i.e., the 1990-91 and 2001 recessions) are still notable in the dynamics of some of the idiosyncratic uncertainties, but were not picked up by the macroeconomic uncertainty series. This suggests that increases in uncertainty during these periods were not as broad-based as during the 1973-75, 1980, and 2007-09 recessions.

In addition, vector autoregressions (VAR) show that innovations to macroeconomic uncertainty generate negative effects on a variety of real economic variables; investment, non-durable and durable consumptions, and GDP all decline after an increase in macroeconomic uncertainty. The impact of uncertainty shocks is not only sizable but also highly

\footnotetext{
${ }^{3}$ See, e.g., Collin-Dufresne and Goldstein (2002), Heston (1993), and Kim et al. (1998).

${ }^{4}$ See Caldara et al. (2012), Jo (2014), Mumtaz and Zanetti (2013), Primiceri (2005), and Justiniano and Primiceri (2008), among others.
} 
persistent, in line with the findings in Jurado et al. (2015) and, to a lesser magnitude, those in Bachmann et al. (2013). In addition, we do not find any evidence supporting subsequent overshooting in economic activity as the uncertainty shock dissipates. This contrasts with previous VAR analyses using traditional proxies for macroeconomic uncertainty, such as the VIX in Bloom (2009) and Caggiano et al. (2014), where the negative effects of uncertainty dissipate quickly, followed by strong rebounds.

We also examine the impact of data revisions on the estimation of economic uncertainty. To the best of our knowledge, ours is the first paper so to do. As macroeconomic variables are constantly revised, uncertainty measures based on the most recent data vintage use a different information set than was previously available to professional forecasters. We find large quantitative differences in the uncertainty series with real-time and revised forecast errors. More specifically, the 1973-75 and 1980 recessions exhibit the largest jumps in our baseline uncertainty index with forecast errors based on the initial release. Yet, a data revision of four underlying series conducted within one quarter after the initial release pushes the uncertainty jump accompanying the 1980 recession up further, leaving its peak at the highest level throughout the entire sample period. On the contrary, uncertainty is at its highest in the Great Recession when the final data vintage is used, although overall dynamics remain similar. Hence, the use of a specific data vintage can be very important, especially when the interest lies in estimating the relative level of macroeconomic uncertainty over time.

Our paper shares some similarities with recent studies focusing on estimating macroeconomic uncertainty. For example, Jurado et al. (2015) fit a factor model to a large crosssection of macroeconomic and financial variables to generate forecasts. They assume that the volatilities of individual forecast errors follow a univariate stochastic volatility process, whose average becomes macroeconomic uncertainty. Rossi and Sekhposyan (2015) use forecast surveys and econometric models for GDP and inflation to construct an uncertainty index from the unconditional historical distribution of forecast errors. Scotti (2013) exploits survey forecasts and creates an uncertainty index as the weighted sum of the squared forecast errors for different indicators. Our approach complements this literature by combining survey forecasts of different indicators in a factor model with stochastic volatility. Thus, we 
jointly estimate indicator-specific as well as macroeconomic uncertainties, providing clear insights about co-movements among indicators. As a result, we are able to shed light on the time-varying contribution of both aggregate and indicator-specific uncertainty for the total variations of the forecasting errors of each indicator.

Our paper is also related to the recent development of literature that applies FSV models to financial and macroeconomic analysis. The FSV model has been widely used in the finance literature as it can parsimoniously capture the variance and covariance of various financial time series using a low-dimensional common factor (Kastner et al. 2014). ${ }^{5}$ On the macroeconomic side, Carriero et al. (2015) introduce a VAR model where macroeconomic variables share a common stochastic volatility factor. Unlike our framework, idiosyncratic volatility is not modeled, since the variations of individual volatilities over time are completely determined by the common factor. Mumtaz and Theodoridis (2015) estimate a dynamic factor model with stochastic volatility with a panel of OECD countries to decompose the time-varying volatilities of macro and financial variables to internationally common, country-specific and variable-specific uncertainties. Finally, Del Negro and Otrok (2008) develop a dynamic factor model with time-varying factor loadings and stochastic volatility to study international business cycles. One common feature in the previous studies is that the evolution of the conditional means of the variables is parametrically linked to the factors. In contrast, our approach fits the FSV model directly to survey forecast errors without jointly modeling the conditional mean along with conditional volatilities, for the first time in the literature to the best of our knowledge. Instead, we outsource the modeling of the conditional mean to professional forecasters. Hence, we provide an estimate of common and idiosyncratic uncertainties through the perspective of professional forecasters.

The rest of the paper is organized as follows. Section 2 introduces the data set. Section 3 provides an exposition of our econometric model. The next section presents results. A VAR analysis in Section 5 shows the responses of real economic activity to innovations in our uncertainty measure. Finally, Section 6 concludes.

\footnotetext{
${ }^{5}$ See, e.g., Aguilar and West (2000) and Chib et al. (2009).
} 


\section{Data}

We use the data from the U.S. SPF, the oldest quarterly survey of macroeconomic forecasts in the U.S. The survey was initially introduced by the National Bureau of Economic Research and the American Statistical Association in 1968, which was then taken over by the Federal Reserve Bank of Philadelphia in June 1990. Surveyed panelists include forecasters from large corporations, Wall Street financial firms, economic consulting firms, and university research centers. We use four variables that have been part of the survey since its inception: real GDP (GDP), unemployment rate (UR), industrial production (IP) and housing starts (HS). With the selected variables, we can obtain a long time series of macroeconomic uncertainty since 1968Q4 until 2015Q2.

Since forecasters are surveyed on a quarterly basis, the most recent quarter of data in their information set is the previous quarter. The forecast submission deadline of the survey tends to occur close to the middle of the quarter (after the Bureau of Economic Analysis advance report of the national income and product accounts [NIPA], which contains the first estimates of the previous quarter's GDP). Hence, for macroeconomic variables released on a monthly basis, forecasters have access to the first month's realized data for the current forecast horizon before the survey is submitted. We use their one-step-ahead forecasts, namely their nowcasts, in order to construct the forecast errors.

The calculation of forecast errors at any point in time is contingent on the realized value of the series. The NIPA data go through substantial revisions, and these revisions can ultimately affect our measurement of uncertainty. Thus, we use the first release, revised data available in one and five quarters after the initial release, as well as the final 2015Q2 vintage data to compute three possible values of forecast errors. When calculating the forecasting errors, we use the consensus forecasts to minimize potential influences from individual forecasting biases. ${ }^{6}$

\footnotetext{
${ }^{6}$ Arai (2014) finds that the SPF consensus forecasts for GDP growth present no systematic biases.
} 


\section{$3 \quad$ Factor Stochastic Volatility Model}

We use the FSV model of Pitt and Shephard (1999) to estimate macroeconomic as well as idiosyncratic uncertainty indexes. First, we define the forecasting error of a variable $i$ in period $t$, denoted as $\varepsilon_{i, t}$, as follows:

$$
\varepsilon_{i, t}=x_{i, t}-\operatorname{median}\left\{E_{1}\left[x_{i, t} \mid I_{t}\right], \cdots, E_{J}\left[x_{i, t} \mid I_{t}\right]\right\}
$$

where $x_{i, t}$ is the realization of variable $i$ in time $t, E_{j}\left[x_{i, t} \mid I_{t}\right]$ is forecaster $j$ 's expectation of variable $i$ for quarter $t$, and median $\left\{E_{1}\left[x_{i, t} \mid I_{t}\right], \cdots, E_{J}\left[x_{i, t} \mid I_{t}\right]\right\}$ captures the median forecast across total $J$ forecaster in each quarter. ${ }^{7}$ Again, one of the key differences of our measure from other uncertainty indexes based on a particular forecasting model is that we obtain $E\left[x_{i, t} \mid I_{t}\right]$ from the consensus forecasts instead of using forecasts from a specific econometric model. The information set $\left(I_{t}\right)$ also has the same time-subscript $t$, as it contains information obtained until the middle of the quarter $t$. That is, for indicators of quarterly frequency, $I_{t}$ includes the first NIPA estimate of $x_{i, t-1}$ that is available only in the middle of the quarter $t$. However, as discussed in the previous section, for monthly macroeconomic indicators such as IP, the first month's value in the quarter $t$ is included in $I_{t}$ along with the first NIPA release of $x_{i, t-1}$.

Next, we postulate that the forecasting error of a macroeconomic series $i$ has a factor structure:

$$
\varepsilon_{t}=\lambda f_{t}+u_{t}
$$

where $\varepsilon_{i, t}=\left[\varepsilon_{1, t}, \cdots, \varepsilon_{n, t}\right]^{\prime}$ is a $(n \times 1)$ vector of forecasting errors; $\lambda=\left[\lambda_{1}, \cdots, \lambda_{n}\right]^{\prime}$ is a vector of factor loadings; $f_{t}$ is a common factor across different $i$ 's; and $u_{t}=\left[u_{1, t}, \cdots, u_{n, t}\right]^{\prime}$ is a vector of idiosyncratic errors, capturing indicator-specific variations. Equation (2) implies that there is a factor that drives the common dynamics across the forecasting errors of total $n$ economic indicators, and that $u_{t}$ captures the remaining indicator-specific variations.

\footnotetext{
${ }^{7}$ We use the median and not the mean forecast across survey respondents to minimize the effect of outliers, especially in the earlier part of the sample.
} 
As in a standard FSV model (e.g., Pitt and Shephard 1999 and Chib et al. 2006), we further assume that $u_{t}$ and $f_{t}$ are conditionally independent Gaussian random vectors.

$$
\left(\begin{array}{c}
u_{t} \\
f_{t}
\end{array}\right) \mid \Sigma_{t}, h_{f, t} \sim N\left(0,\left[\begin{array}{cc}
\Sigma_{t} & 0 \\
0 & h_{f, t}
\end{array}\right]\right),
$$

where $\Sigma_{t}$ are a $n \times n$ diagonal matrix of time-varying idiosyncratic volatilities. In other words,

$$
\Sigma_{n, t}=\left[\begin{array}{cccc}
h_{1, t} & 0 & \cdots & 0 \\
0 & h_{2, t} & \cdots & 0 \\
\vdots & \vdots & \ddots & \vdots \\
0 & 0 & \cdots & h_{n, t}
\end{array}\right]
$$

The common as well as indicator-specific volatilities follow independent stochastic volatility processes:

$$
\begin{aligned}
& \log h_{f, t}=\log h_{f, t-1}+\sigma_{f} \eta_{f, t} \\
& \log h_{i, t}=\log h_{i, t-1}+\sigma_{i} \eta_{i, t}
\end{aligned}
$$

where $\sigma_{f}$ and $\sigma_{i}$ 's are time-invariant parameters determining the variability of the volatilities, and $\eta_{f, t}$ and $\eta_{i, t}$ capture innovations to volatility. One reason that the stochastic volatility model has been widely adopted in literature is its flexibility due to the innovation term in the volatility process in addition to that of the first moment. Applied to our set-up, it is possible to examine shocks to the volatility process, which can be uncorrelated with unexpected variations in the level of forecast errors. ${ }^{8}$

The key estimate of interest is the time-varying standard deviations of the factor, i.e., $\left\{\sqrt{h_{f, t}}\right\}$, which we define as a measure of the macroeconomic uncertainty: the time series of macroeconomic uncertainty captures the volatility of a common driver that simultaneously affects the magnitude of forecasting errors across different real activity indicators. Other

\footnotetext{
${ }^{8}$ Hence, the resulting shock processes can be included in a univariate regression framework to gauge the effects of uncertainty shocks in a straightforward way. For example, the shock processes can be used to obtain impulse responses to an uncertainty shock by local projections à la Jordà (2005).
} 
important estimates are the time-varying standard deviations of idiosyncratic errors, i.e., $\left\{\sqrt{h_{i, t}}\right\}$. These idiosyncratic volatility series will capture the size of indicator-specific shocks, which are orthogonal to the common factor by construction. It is worthwhile to note again that our framework hence yields both common and indicator-specific uncertainty indexes, which are consistently modeled and estimated in one step.

The model is estimated using Bayesian methods, since it features high dimensionality as well as non-linearity. The Bayesian methods deal with such features by separating parameters into several blocks, which greatly simplifies the estimation process. In particular, the Markov Chain Monte Carlo (MCMC) algorithm breaks the parameters into several blocks and repeatedly draws from their conditional posterior distributions in order to simulate the joint posterior distribution. While details regarding the MCMC algorithm is provided in Appendix A, here we briefly summarize steps in the estimation procedure as follows:

1. Assign initial values for $\lambda,\left\{f^{T}\right\}, \sigma_{f},\left\{h_{f}\right\}$, and $\sigma_{i}$ and $\left\{h_{i}\right\}$ for all $i$.

2. Draw $\lambda$ from $p\left(\lambda \mid \varepsilon^{T}, f^{T}, \sigma_{f}, \sigma_{i}, h_{f}^{T}, h_{i}^{T}\right)$.

3. Draw $\left\{f^{T}\right\}$ from $p\left(f^{T} \mid \varepsilon^{T}, \lambda, \sigma_{f}, \sigma_{i}, h_{f}^{T}, h_{i}^{T}\right)$.

4. Draw $\sigma_{f}$ and $\sigma_{i}$ s from $p\left(\sigma \mid \varepsilon^{T}, f^{T}, h_{f}^{T}, h_{i}^{T}\right)$.

5. Draw $\left\{h_{f}\right\}$, and $\left\{h_{i}\right\}$ 's from $p\left(h \mid \varepsilon^{T}, f^{T}, \sigma_{f}, \sigma_{i}\right)$.

6. Go to step 2.

The conditional independence across $t$ and $i$ as well as of $f_{t}$ and $u_{i, t}$ 's simplifies the estimation procedure. More specifically, steps in the Gibbs sampler, such as drawing factor loadings, volatility states and the variance of volatilities (i.e., steps 2, 4 and 5) break down to drawing from a univariate process. Likewise, step 3 becomes estimating a Bayesian regression of forecast errors on factor loadings in every period $t$ with known error variance.

We collect 5,000 draws by storing every 10th draw in order to avoid potential autocorrelation across draws. Thus, we iterate over the sampler a total of 80,000 times, but discard the first 30,000 draws of parameters. We follow the common identification scheme of a factor model that sets the first factor loading (of GDP) equal to unity. However, the resulting baseline index of macroeconomic uncertainty is robust to equalizing other factor loadings to one or to changing the ordering of variables. The choice of prior distributions 
Table 1: Summary Statistics of Posterior Draws of Factor Loadings

\begin{tabular}{l||lccc}
\hline \hline & GDP & IP & UR & HS \\
\hline & & & & \\
Median & 1 & 1.39 & -1.07 & 0.40 \\
Std. Dev. & - & 0.33 & 0.25 & 0.16 \\
\hline
\end{tabular}

Note: This table shows the median and standard deviations calculated from the posterior draws of four factor loadings. Since our identification strategy is to set the loading of GDP to unity, the standard deviation is not reported for GDP.

and their parameter values is very similar to that of Pitt and Shephard (1999). A detailed description of the prior distribution setup and the MCMC algorithm is provided in Appendix A.

\section{Results}

\subsection{Estimated Macroeconomic and Idiosyncratic Uncertainties}

We plot our baseline macroeconomic uncertainty series in Figure 1: the solid line is the median posterior draw $\left(\left\{\sqrt{h_{f, t}}\right\}_{t=1}^{T}\right)$ and the shaded area represents the 95 percent posterior credible set. For our baseline estimates, we use the first data release to calculate the forecasting errors. ${ }^{9}$

There are three main spikes in macroeconomic uncertainty, all associated with deep recessions. The first spike was observed during the 1973-75 recession, the second during the 1980 recession, and the last one during the recent Great Recession. The highest increase in macroeconomic uncertainty occurred during the 1980 recession. It is also clear from the figure that, in general, the level of macroeconomic uncertainty was significantly higher in the 1968-85 period than from 1985 until the Great Recession, consistent with the findings in Kim and Nelson (1999) and McConnell and Perez-Quiros (2000). The index shows some increase around the 1991 recession, but it is a small one in comparison with the three critical spikes. The 2001 recession, on the other hand, was accompanied by very mild increases in macroeconomic uncertainty.

Table 1 reports the median posterior draws of factor loadings. For identification of a

\footnotetext{
${ }^{9}$ We assess the effect of data revisions on our uncertainty measure in Section 4.3.
} 
Figure 1: Estimated Macroeconomic Uncertainty Series

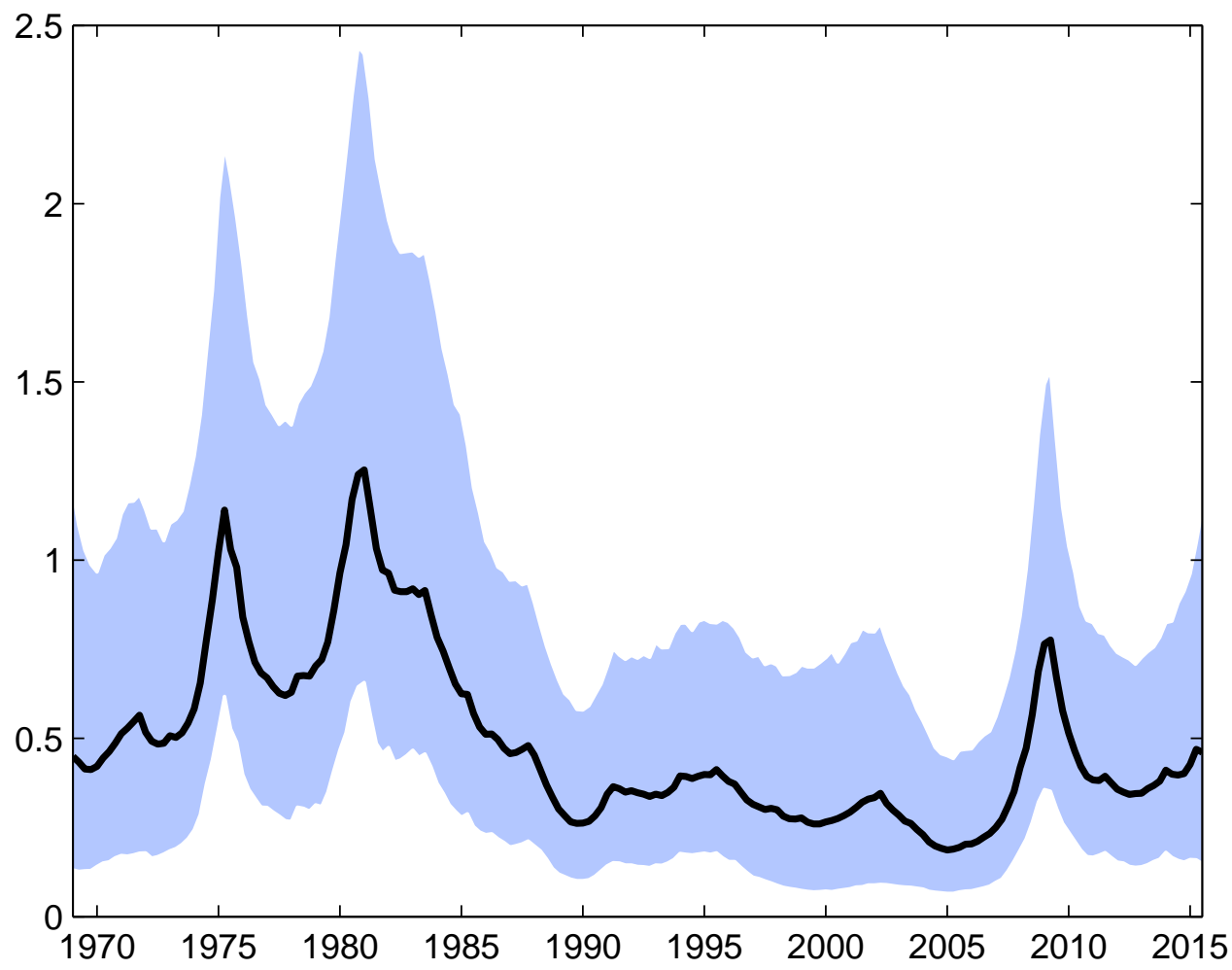

Note: This figure plots the baseline macroeconomic uncertainty series estimated using the first-released data. The black solid line is the median posterior draws of the time-varying standard deviation of a common factor across forecasting errors of four macroeconomic indicators. The shaded area is the 95 percent posterior credible set. 
factor and factor loadings, we set the factor loading of GDP to unity, as mentioned in the previous section. However, the relative sizes of the factor loadings and subsequently the estimated series of uncertainty are robust to different normalization. ${ }^{10}$ We find that housing starts load least on the common factor, while the loadings of the other three variables are in a comparable range.

Using the median posterior draws, we further examine how much of the total variation in the forecasting errors of each indicator is driven by the common versus idiosyncratic volatilities. This is calculated by using the factor structure of our model. In particular, our model implies a total variance of each variable in each period, $\operatorname{var}\left(\varepsilon_{i, t}\right)$, to be

$$
\begin{aligned}
\operatorname{var}\left(\varepsilon_{i, t}\right) & =\operatorname{var}\left(\lambda_{i} f_{t}+u_{i, t}\right) \\
& =\lambda_{i}^{2} \operatorname{var}\left(f_{t}\right)+\operatorname{var}\left(u_{i, t}\right) \\
& =\lambda_{i}^{2} h_{f, t}+h_{i, t},
\end{aligned}
$$

as the factor and idiosyncratic error terms are assumed to be uncorrelated. We then measure the size of the total common variation driven by macroeconomic uncertainty in each period as $\lambda_{i}^{2} \operatorname{var}\left(f_{t}\right)=\lambda_{i}^{2} h_{f, t}$, incorporating the heterogeneity due to the difference in factor loadings. Next, we compare $\sqrt{\operatorname{var}\left(\varepsilon_{i, t}\right)}$ and $\lambda_{i} \sqrt{h_{f, t}}$ to investigate the contributions of the common and idiosyncratic uncertainties.

Figure 2 plots the estimated total variation with the part explained by macroeconomic uncertainty for each indicator. For most variables except housing starts, the most notable spikes in the total variation are driven to a large extent by macroeconomic uncertainty. Moreover, recessions that were not accompanied by distinct increases in macroeconomic uncertainty, as in the 1991 and 2001 recessions, do show up in the total variations of unemployment and, to a smaller extent, GDP and industrial production.

During the period of 1985 to 2007, when the baseline macroeconomic uncertainty index was relatively subdued, idiosyncratic volatilities explain a large fraction of the total volatilities of the different series. In the case of GDP, the share of idiosyncratic volatility takes

\footnotetext{
${ }^{10}$ In addition, while the medians change depending on which vintage is used to calculate forecast errors, the relative sizes of the most factor loadings also remain robust to the change of the data vintages. The results based on different data vintages are available upon request.
} 
Figure 2: Total Variation versus Macro Variation

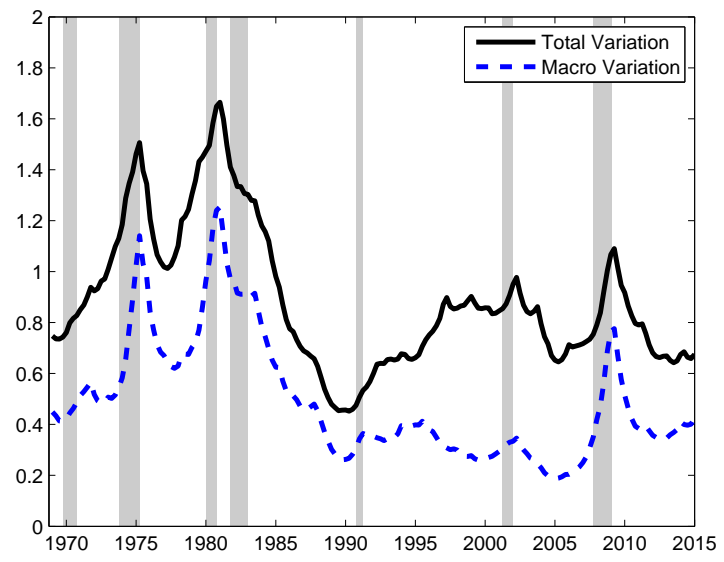

(a) GDP

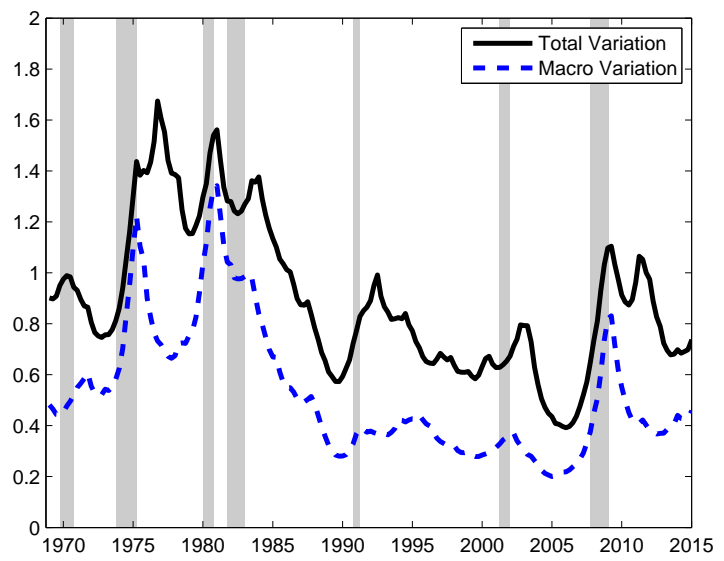

(c) Unemployment

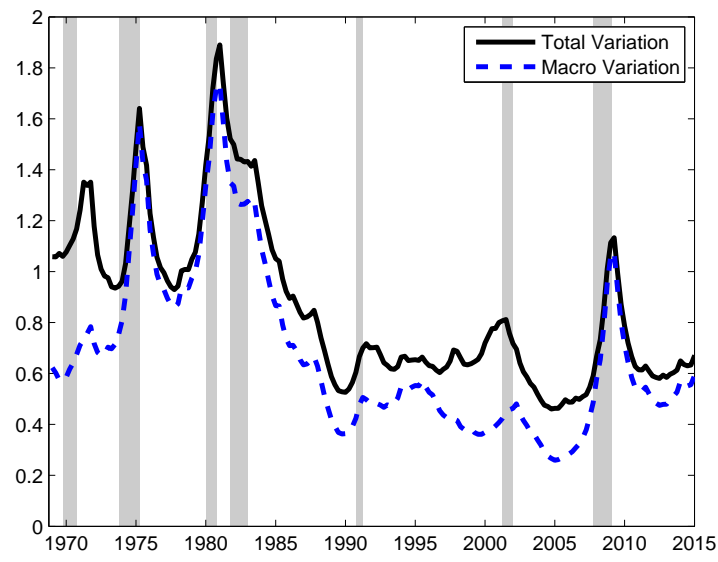

(b) IP

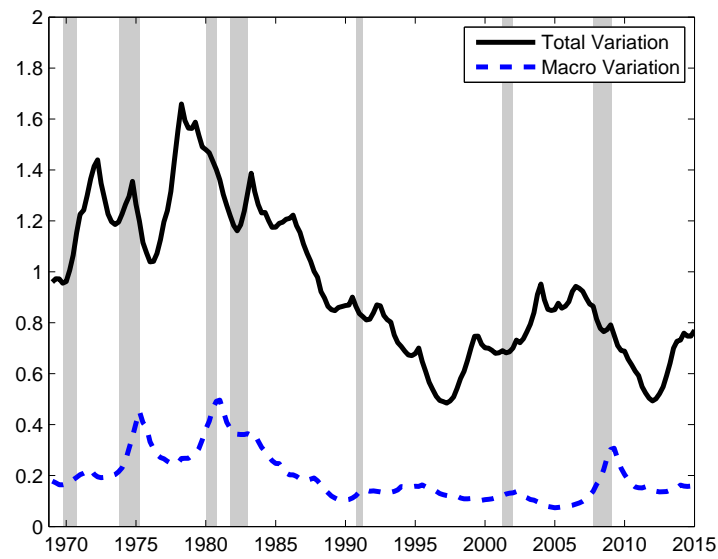

(d) Housing Starts

Note: This figure shows how much of total variation of each variable is explained by the macroeconomic uncertainty. The grey line is the total variation of one variable (defined as standard deviation), and the black line is the macroeconomic uncertainty multiplied by a factor loading. All calculations are based on the median posterior draws. 
more than 50 percent of the total variation of GDP forecasting errors during this period. Finally, it is interesting to note that the variation of housing starts contributes the least to the macroeconomic uncertainty, and it leads the total volatility of the other indicators. Interestingly, the idiosyncratic uncertainty of housing starts was on an increasing trend from the mid-1990s to the Great Recession.

\subsection{Comparison with Other Common Measures of Uncertainty}

Various attempts have been made recently to quantify economic uncertainty: we compare our baseline measure with a measure based on forecast disagreements, the VIX, and finally, the one introduced in Jurado et al. (2015).

\section{Forecast disagreement}

A widely used proxy for uncertainty based on survey forecasts is forecast disagreement, commonly measured as the interquartile range (e.g., Bachmann et al. 2013). Underlying this practice is the assumption that predictions of forecasters are more likely to be close to each other when economic uncertainty is low. However, forecast disagreement may just reflect heterogeneous, but not uncertain, beliefs. ${ }^{11}$ Figure 3 plots the forecast disagreements of the four economic series underlying our baseline model, along with the total variations of median forecast errors calculated as in (5). The forecast disagreement is measured as the interquartile ranges, i.e., the 75 th percentile minus the 25 th percentile of individual forecasts.

In general, for each indicator, both disagreement and total variation from our model exhibit similar dynamics over time. However, disagreements are notably more volatile than total variations. In addition, all variables show episodes where the disagreement and total variation deviate substantially from each other.

We further investigate the relationship between our macroeconomic uncertainty measure and an analogous, disagreement-based proxy of macroeconomic uncertainty. We take the averages of disagreement of the four indicators to construct a comparable series. Panel

\footnotetext{
${ }^{11}$ See, for example, Mankiw et al. (2004), Lahiri and Sheng (2010), and Sill (2012) for more detailed discussions of measuring uncertainty using forecast disagreement.
} 
Figure 3: Stochastic Volatility and Dispersions

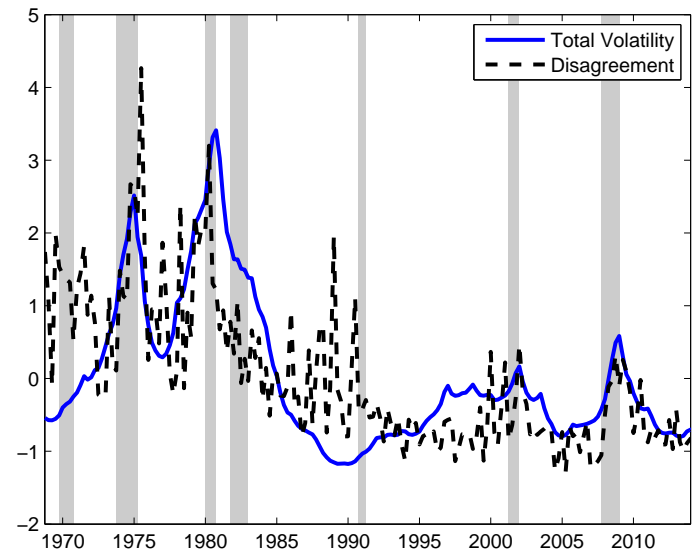

(a) GDP

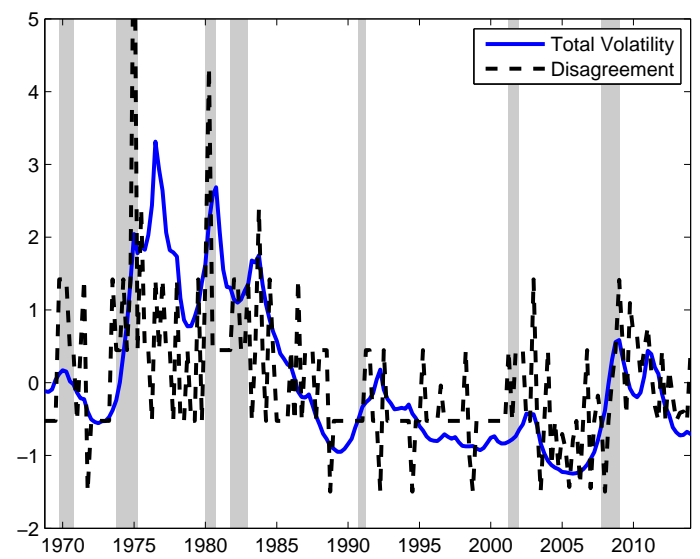

(c) Unemployment

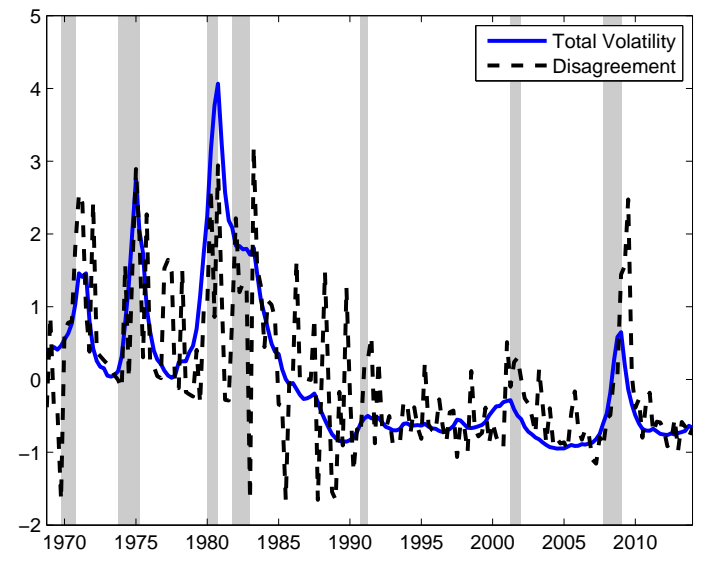

(b) IP

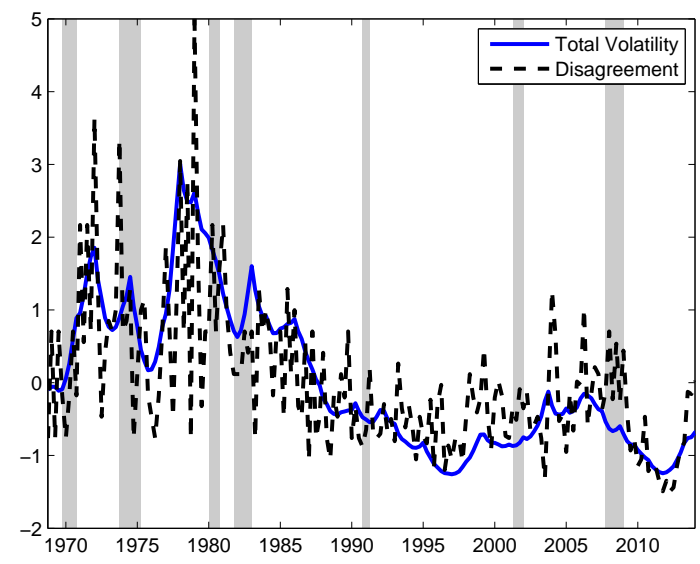

(d) Housing Starts

Note: This figure compares forecast disagreement from the SPF to total variation of underlying individual series calculated as (5). The forecast disagreement is measured as the interquartile ranges, i.e., the 75th percentile minus the 25 th percentile of individual forecasts. All series are standardized. 
(a) in Figure 4 presents the resulting average disagreement series along with our baseline measure of macroeconomic uncertainty. The average disagreement series evolves closer to our macroeconomic index, compared with the dynamics of individual disagreements; the three major spikes in disagreement coincide with the three main episodes of uncertainty increases in our baseline index.

\section{VIX}

Since employed in Bloom (2009), the VIX index has been one of the most commonly used measures of uncertainty. The VIX index quantifies implied volatility using a weighted average of the S\&P 500 call-and-put option prices for the next 30 days and is available on a daily basis. Thus, it mainly captures the financial volatility. Panel (b) in Figure 4 plots the VIX along with our baseline measure of macroeconomic uncertainty after standardization for comparison. The VIX is more volatile and has more peaks, some of which are specifically due to financial market episodes that did not spill over to the real side of economy. More importantly, the VIX collectively reflects both stock market uncertainty and risk aversion, and, as a result, some of the jumps are mainly due to increases in risk aversion rather than those in uncertainty, as shown in Bekaert et al. (2013).

\section{Jurado et al. (2015)'s macroeconomic uncertainty index}

The macroeconomic uncertainty measure constructed in Jurado et al. (2015) is based on the same definition of uncertainty: it is the time-varying conditional second moment of unexpected variations that affects forecasting errors of a number of economic indicators simultaneously. Our approach and Jurado et al.'s measure share an additional similarity, as both employ a stochastic volatility model as well as a factor structure. However, Jurado et al. use the factor structure mainly for forecast generation: a large (dynamic) factor model is built encompassing 132 macroeconomic and 147 financial series, where the forecasts for all series are computed. These forecasts are used to calculate forecast errors of each series, after which a univariate stochastic volatility process is fitted to 132 macroeconomic series. Finally, the estimated volatilities are averaged to form a macroeconomic uncertainty index.

Thus, our approach contrasts with that of Jurado et al. (2015) in that, in our approach, 
Figure 4: Comparison with Other Measures

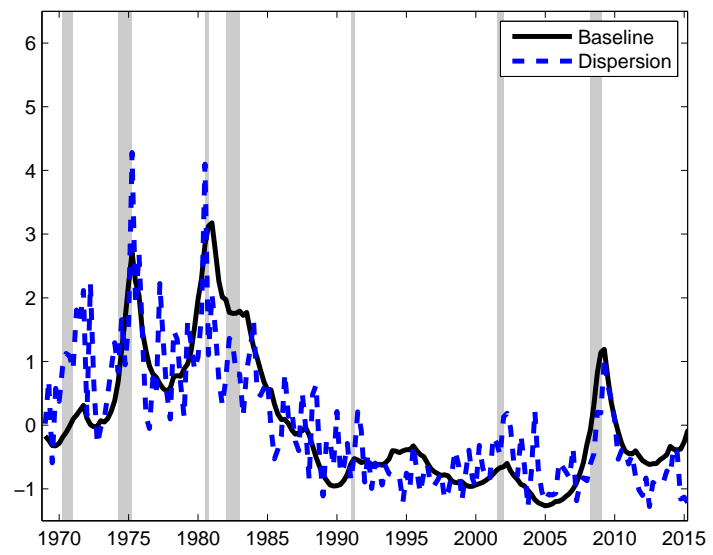

(a) Disagreement

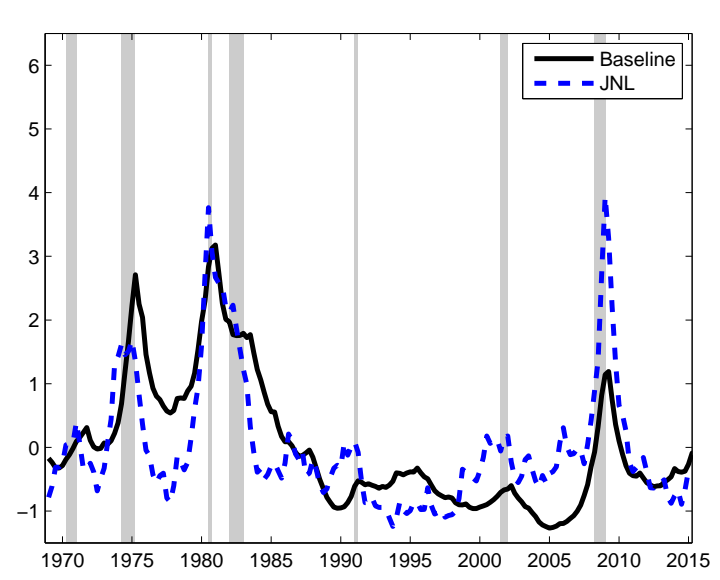

(c) JNL

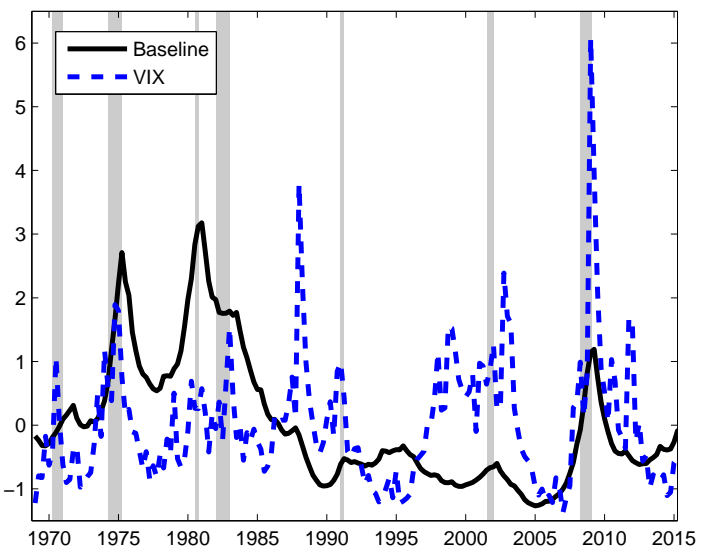

(b) VIX

Note: This figure compares our baseline macroeconomic series to other widely used indexes of uncertainty. Panel (a) plots the averages of forecast disagreement of the four economic indicators; (b) the VIX; and (c) the Jurado et al. (2015) uncertainty series, along with our baseline measure, respectively. All series are standardized. 
(i) forecasts are simply taken from a survey and (ii) macroeconomic and indicator-specific uncertainties are jointly modeled and estimated in one step. In addition, the number of underlying economic indicators is drastically different: while our measure is based on four indicators, Jurado et al. take into account close to 300. Despite the differences, it is surprising that both measure show very similar dynamics and identify the same three main episodes of high uncertainty, as illustrated in Panel (c) in Figure 4. This reflects the extensive information content in survey forecasts: Zarnowitz and Braun (1993) document that professional forecasters in the SPF generate forecasts based on various econometric models, leading indicators and surveys as well as a number of available macroeconomic and financial data, integrating information from a wide range of sources. Consequently, our approach removes predictable variations very effectively, providing a parsimonious yet efficient tool for the estimation of uncertainty. The information content in survey forecasts is examined again in Section 4.4.

\subsection{The Impact of Data Revisions}

Macroeconomic data go through substantial revisions after their initial release. ${ }^{12}$ Likewise, macroeconometric analysis using latest available vintage data often results in different conclusions from work that takes real-time issues into account (Orphanides 2001 and Orphanides and Van Norden 2002, for example). A large body of papers has also shown that real-time data issues are particularly important for evaluating the forecasting power of econometric models (Diebold and Rudebusch 1991, Faust et al. 2003, Amato and Swanson 2001, and Ghysels et al. 2014, among many others). However, previous studies focus on the effects on point forecasts (i.e., the conditional mean); likewise, the effect of data revision on the estimation of the conditional second moments has not been documented, to the best of our knowledge. Nonetheless, data revisions should also have an important impact on the measurement of uncertainty, since they directly affect the magnitude of forecast errors. Our baseline measure is estimated with forecast errors computed using the first data release; in this section, we also examine to what extent our macroeconomic uncertainty index differs, if we use vintages available in one and five quarter(s) after the initial release as well as

\footnotetext{
${ }^{12}$ See Faust et al. (2005), Aruoba (2008) and Amir Ahmadi et al. (2015) for more details on the empirical properties of data revisions.
} 
Figure 5: Macroeconomic Uncertainty Based on the Different Vintages

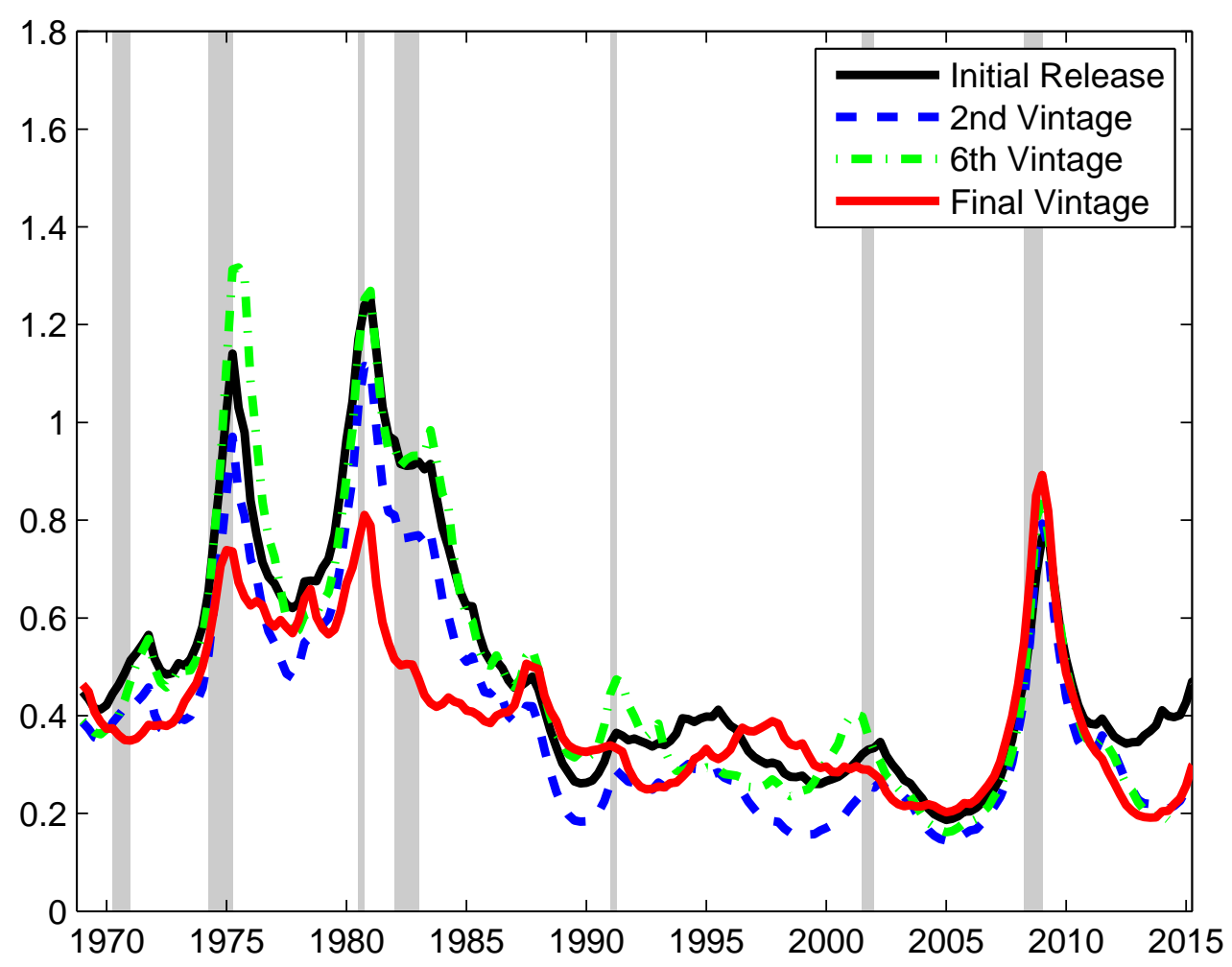

Note: This figure compares the baseline macroeconomic uncertainty factor (the first release) with the uncertainty factor estimated with data from different vintages. The solid line is our baseline uncertainty index, the blue dashed line is the one where forecasting errors of each variable are computed using the revised data available in one quarter after the initial release, the green dash-dot line, is the 6th vintage, and the red line, the final vintage data.

the final 2015Q2 vintage to calculate the forecast errors. Hence, for the first time in the literature, to the best of our knowledge, our paper examines the effects of data revisions for the estimation of macroeconomic volatility.

Figure 5 shows the macro uncertainty index based on the first-released data (the baseline measure), the data revised in one and five quarter(s) after the initial release, and the final vintage data. The final vintage data differ from other vintages, as each data point has gone through different numbers of revisions, that is, data from the further past have been revised multiple times, while more recent data may have undergone only a couple of revisions.

The correlations among all four indexes are high, peaking substantially at the same 
periods as the baseline index, i.e., the 1973-75, 1980, and 2008-09 recessions. Therefore, we find that the estimated series of uncertainty using different data vintages largely coincide under our framework. Nonetheless, we find quantitative differences across the four series. Most notably, the relative size of the peaks changes depending on the data vintage used to calculate forecasting errors. In other words, the jump in uncertainty during the 1980 recession is shifted upward when the second vintage is used, pushing the level of uncertainty up to the highest level. In contrast, with the forecast errors based on the initial data release and the sixth vintage, the uncertainty during the recessions in the pre-Great Moderation periods, i.e., the 1973-75 and 1980 recessions, are higher than the level of uncertainty during the last recession. However, the difference is most stark when the final vintage data are used. In this case, the Great Recession is associated with the largest jump in uncertainty since the beginning of the series, more in line with the dynamics of uncertainty captured by the VIX and the Jurado et al. (2015) index.

In sum, our findings suggest that, while overall dynamics of both macroeconomic and idiosyncratic uncertainties remain robust, they exhibit differences, particularly in the relative size of major peaks over time, depending on a particular data vintage chosen. For instance, macroeconomic uncertainty based on the final vintage data will likely underestimate the actual volatility faced by professional forecasters in the 1970s and 1980s in comparison with the level during the Great Recession.

\subsection{How Important Is the Information in the Survey?}

It is important to remove predictable components from the economic indicators when estimating macroeconomic uncertainty so as not to attribute the predictable variation to unpredictable shocks. As highlighted by Jurado et al. (2015), the most-commonly used proxies of uncertainty — such as stock market volatility (i.e., VIX) and forecast dispersions - do not account for this fact.

Several papers have documented that the predictive ability of survey forecasts is a difficult benchmark for econometric forecasting models to beat, especially at short horizons (see Ang et al. 2007; Faust and Wright 2013; Aiolfi et al. 2011). Consequently, survey forecasts efficiently control for predictable variation in the economic indicators. To examine 
the effectiveness of survey forecasts in removing predictable variations, here we re-estimate our factor stochastic volatility model using forecasting errors from simple autoregressive (AR) models:

$$
y_{i, t}=\alpha_{i}+\sum_{j=1}^{p} \beta_{i, j} y_{i, t-j}+\gamma_{1} y_{i, t}^{1}+\gamma_{2} y_{i, t-1}^{2}+\gamma_{3} y_{i, t-1}^{3}+\epsilon_{i, t}
$$

where $p$ is the lag length chosen based on the Akaike information criterion with a rolling fixed window of 60 observations. For the variables released at a monthly frequency, the monthly values reported, i.e., the first-month value in quarter $t\left(y_{i, t}^{1}\right.$, only if the release date is before the survey deadline) and the third- and second-month values of quarter $t-1$ $\left(y_{i, t-1}^{3}\right.$ and $\left.y_{i, t-1}^{2}\right)$ are augmented to the AR model, to closely mimic information available to professional forecasters at the time of the survey. ${ }^{13}$ It is worthwhile to note that the real-time data available in each quarter $t$ are used for the AR models to match our baseline index more closely.

We then estimate stochastic volatility of a common factor using $\hat{\epsilon}_{i, t}$, the forecast errors from the AR model above, for each of our four variables. The dotted line in Figure 6 plots the estimated macroeconomic volatility with the AR forecast errors. The AR-based macroeconomic uncertainty index is considerably higher throughout the whole sample period and more volatile than our baseline index based on survey forecasts. The result implies that a significant share of the forecast errors from the AR models are indeed captured by consensus forecasts, especially during recessions. Hence, simple statistical models such as AR have not only larger forecasting errors but also more volatile ones, which are then subsequently attributed to higher macroeconomic uncertainty. ${ }^{14}$ More importantly, this analysis shows that using a consensus survey forecast is a parsimonious and effective way of eliminating the predictable variations from economic variables, thereby providing a more

\footnotetext{
${ }^{13}$ The forecast errors from the above AR model are available at the Federal Reserve Bank of Philadelphia website. In addition, Stark (2010) provides a detailed description regarding the model and real-time available information sets.

${ }^{14}$ The Real-Time Data Research Center at the Federal Reserve Bank of Philadelphia provides statisticsrelated SPF forecast errors by comparing the forecast errors from the SPF with those from other simple but widely used forecasting models: no-change forecast, iterative AR forecast, and horizon-specific AR forecast. The SPF forecast for $t=0$, i.e., the nowcasts, of the four variables we use have consistently lower RMSEs compared with other forecasting errors, and the differences are statistically significant. This further indicates that survey forecasts integrate wider sets of information than a simple statistical mode.
} 
Figure 6: Macroeconomic Uncertainty: AR versus Surveys

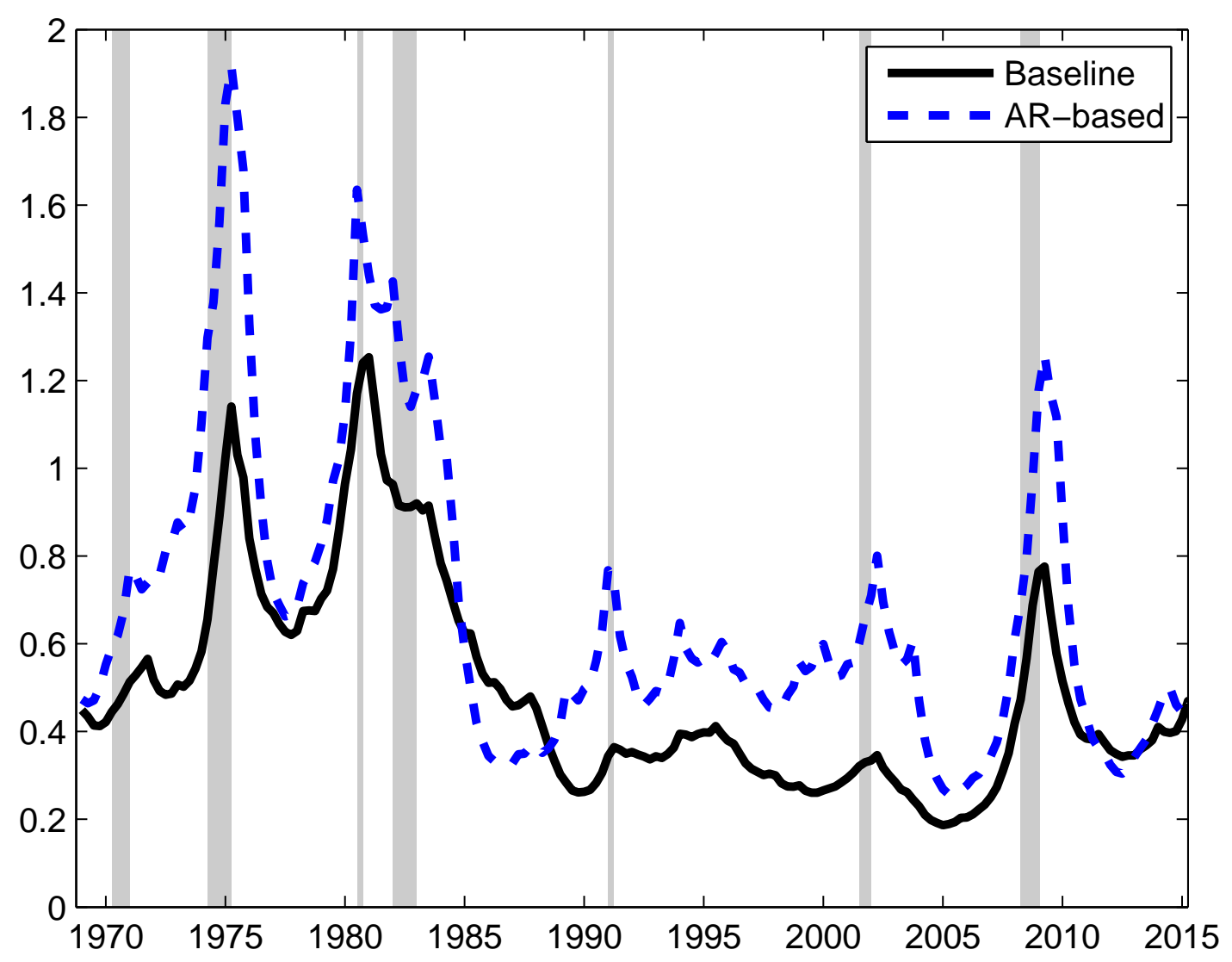

Note: This figure compares the baseline macroeconomic uncertainty index (estimated with survey forecast errors) with the one estimated with errors obtained from the AR model as (6). 
accurate measure of uncertainty faced by economic agents.

\section{Innovations to Uncertainty and Macro Dynamics}

In this section, we examine the dynamic relationship between our measure of macroeconomic uncertainty and a set of macroeconomic indicators using a standard recursively identified VAR. Previous studies using proxies for macroeconomic uncertainty, such as the VIX in Bloom (2009), tend to find a significantly negative, but short-lived impact of uncertainty on economic activity, followed by an overshoot as economic activity rebounds. In contrast, studies that estimate macroeconomic uncertainty, as Jurado et al. (2015), find that these shocks have a much more persistent effect on economic activity, and no evidence of a strong rebound and overshooting.

Our benchmark specification of a VAR comprises six variables, in the following order: $\log (\mathrm{S} \& \mathrm{P}$ index $)$, uncertainty, $\log$ (private investment), $\log$ (non-durable consumption expenditure), $\log$ (durable consumption), $\log ($ GDP). The VAR is estimated in levels with four lags. A natural choice of the ordering of variables is not clear, as our uncertainty measure should react to real activity shocks within a quarter, while it is also possible that other real variables respond to uncertainty during the same quarter. We follow previous literature and order our uncertainty series before the real activity indicators, but after the S\&P index. $^{15}$

Figure 7 presents the estimated dynamic responses of the various economic activity measures to a one standard deviation innovation to macroeconomic uncertainty. All of the economic activity variables show a significant and persistent decline following the shock, supporting the findings of long-lived negative effects of uncertainty as in Jurado et al. (2015) and, to a lesser magnitude, Bachmann et al. (2013). In contrast to Bloom (2009), we find no evidence of overshooting in economic activity as the uncertainty shock dissipates.

We further conduct a comparison of our impulse response functions with the ones obtained with other estimates and proxies for macroeconomic uncertainty. Figure 8 plots

\footnotetext{
${ }^{15}$ See, for example, Bloom (2009), Jurado et al. (2015), Bachmann et al. (2013), Aastveit et al. (2013), and Caggiano et al. (2014). Our findings are robust to the changes of the variable ordering. Results from different versions of VARs are available upon request.
} 
Figure 7: Responses to Innovations to Macroeconomic Uncertainty
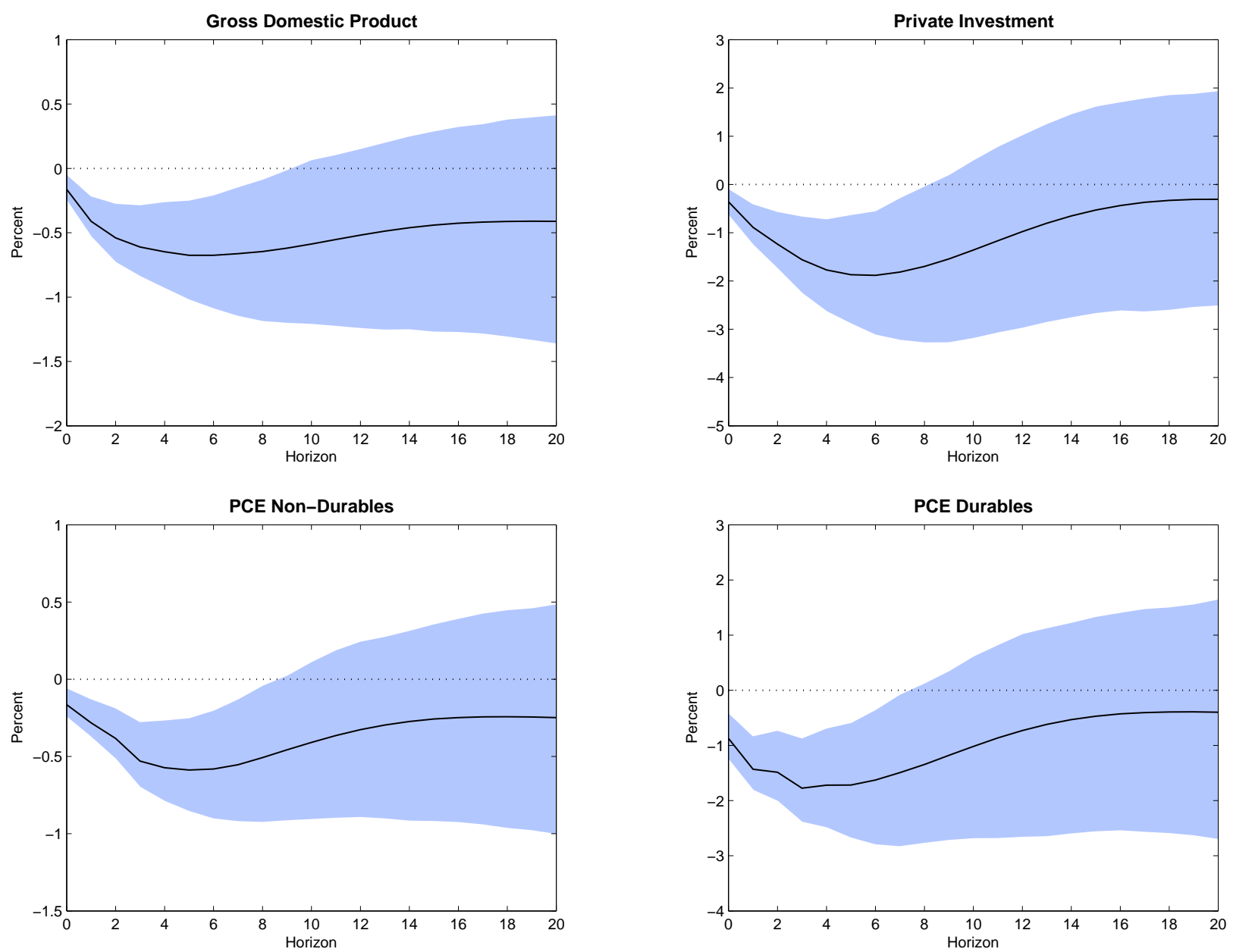

Note: This figure shows the response of various macroeconomic variables to uncertainty shocks in a 6variable VAR with the following variables and ordering: S\&P index, macroeconomic uncertainty index, real private investment, real personal consumption expenditures on non-durables, real personal consumption expenditures on durables, real GDP. The VAR is estimated in levels with 4 lags. All variables, except the uncertainty index, are measured in logs. The shaded area represents two standard deviation bands using Kilian (1998)'s bootstrap-after-bootstrap method. 
Table 2: Variance Decomposition for the Baseline VAR

\begin{tabular}{lllll}
\hline \hline Quarters & RPI & PCE-ND & PCE-D & GDP \\
\hline 1 & 4.64 & 6.42 & 9.99 & 6.09 \\
2 & 10.25 & 11.46 & 19.95 & 16.07 \\
4 & 15.15 & 21.87 & 23.85 & 21.70 \\
8 & 19.67 & 27.16 & 24.47 & 25.35 \\
20 & 17.89 & 19.54 & 16.68 & 23.56 \\
\hline
\end{tabular}

Note: This table shows forecast error variance decomposition for our baseline VAR with variables in the following order: S\&P index, uncertainty, real private investment (RPI), real personal consumption expenditures on non durables (PCE-ND), real personal consumption expenditures on durables (PCE-D), GDP. The VAR is estimated in levels with 4 lags. All variables, except our uncertainty measure, enter the VAR in logs.

responses to innovations in our baseline uncertainty series, as well as the Jurado et al. (2015) index (JLN), the average disagreement introduced in Section 4.2 and the VIX. There is a clear divergence in results. Both innovations to our measures and the JLN measure of macroeconomic uncertainty result in large and persistent drops in economic activity. On the other hand, innovations to proxies of macroeconomic uncertainty, the disagreement and the VIX, result in very small and short-lived negative impacts on economic activity, followed by strong rebounds.

To verify the quantitative importance of an uncertainty shock, Table 2 reports the forecast error variance decomposition for the real economic activity variables included in the VAR. The decomposition shows that an uncertainty shock can explain a maximum of 19.67 percent (real private investment) to 27.16 percent (non-durable consumption) of the variance of various real economic activity measures within 5 years after the shock. These numbers are in line with those reported by Bachmann et al. (2013) and Jurado et al. (2015).

\section{Conclusion}

This paper analyzes the evolution of economic uncertainty from 1968Q4 to 2015Q2 as perceived by professional forecasters. Using a FSV framework proposed by Pitt and Shephard (1999) permits us to jointly model and estimate time-varying macroeconomic and indicatorspecific uncertainties from the consensus forecast errors of different economic indicators. Our baseline macroeconomic uncertainty index is persistent with all major spikes associ- 
Figure 8: Responses with Alternative Measures of Uncertainty
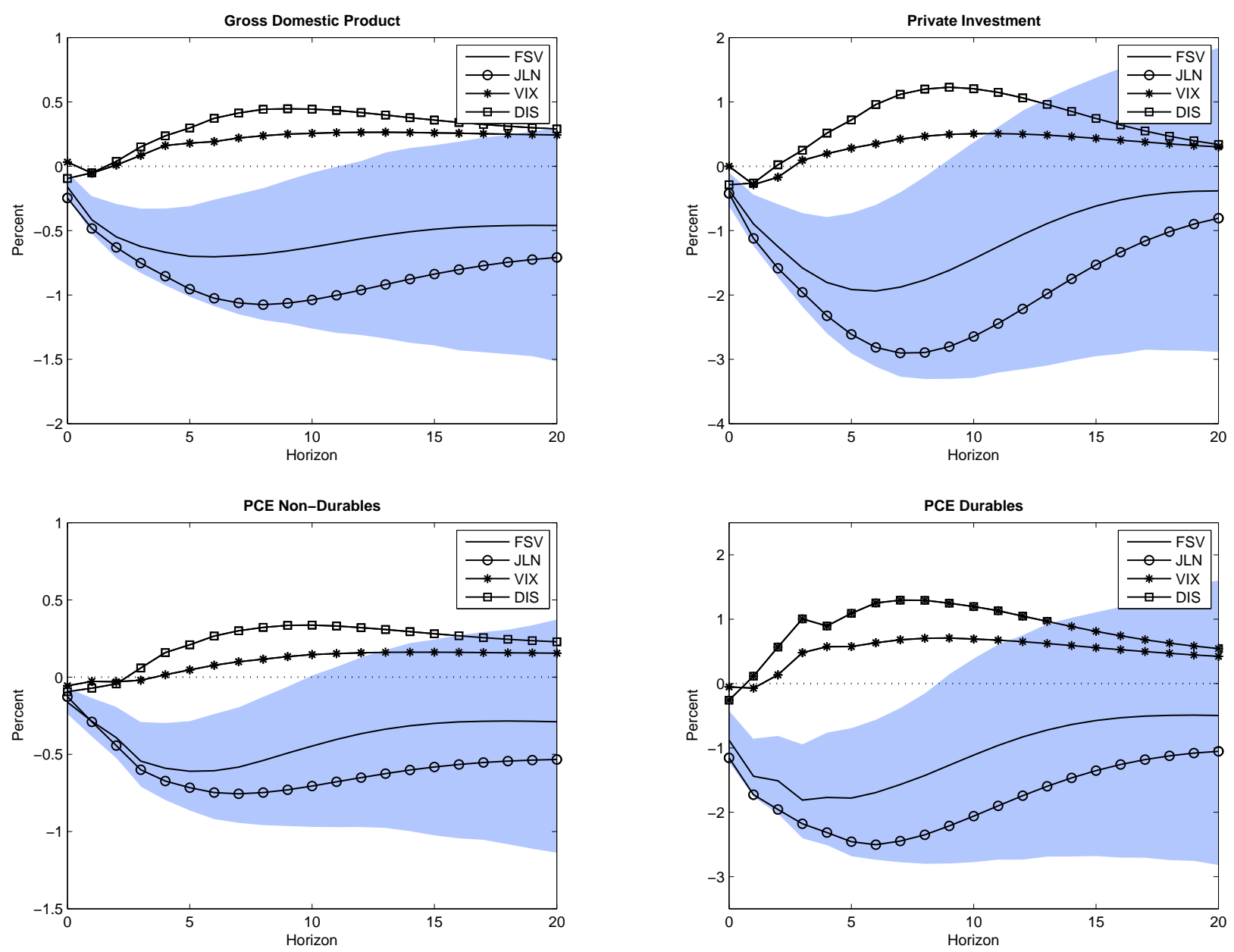

Note: This figure shows the response of various macroeconomic variables to uncertainty shocks in a 6 variable VAR using alternative uncertainty indexes: FSV is our baseline measure of macroeconomic uncertainty as perceived by professional forecasters; JLN is the measure proposed by Jurado et al. (2015); VIX is the stock market implied volatility used by Bloom (2009); and DIS is the average disagreement as discussed in Section 4.2. The shaded area represents one standard deviation bands using Kilian (1998)'s bootstrap-after-bootstrap method. 
ated with deep economic recessions (the 1973-75, 1980, and 2007-09 recessions), consistent with Jurado et al. (2015). However, other recessions (i.e., the 1990-91 and 2001 recessions) are still notable in the dynamics of some of the idiosyncratic uncertainties but were not picked up by the macroeconomic uncertainty series. Overall, we find that macroeconomic uncertainty was higher in the 1968-85 period compared with the post-1985 period.

Using survey forecasts enables us to keep our framework simple and straightforward due to their extensive information contents. Our baseline macroeconomic uncertainty index shows dynamics similar to those of the Jurado et al. (2015) index, despite the substantial differences in the number of underlying series. This highlights the informativeness of survey forecasts and further their effectiveness in removing predictive variations from economic indicators so as not to erroneously attribute them to unexpected shocks. A comparison with an AR forecast-based index also confirms the efficiency of using survey forecasts, as the AR-based uncertainty measure is considerably higher throughout the whole sample period.

Furthermore, we document for the first time in the literature how data revisions affect the estimated evolution of macroeconomic uncertainty. In particular, we show that the relative size of major uncertainty peaks changes depending on a specific vintage chosen to calculate forecast errors. We also conduct a VAR analysis to investigate the dynamic relationship between uncertainty and real economic variables. A one-standard deviation increase in our baseline uncertainty index results in a significant and persistent decrease in various measures of economic activity such as investment, durable and non-durable consumptions, in line with the findings in Bachmann et al. (2013) and Jurado et al. (2015). However, this evidence is at odds with the short-lived negative impact followed by a strong rebound, as suggested by Bloom (2009). 


\section{Appendix}

\section{A Bayesian Estimation Method}

\section{A.1 Prior Distributions and Starting Values}

Our choice of prior distributions and their parameter values is very similar to that of Pitt and Shephard (1999). The prior distribution for factor loadings is the Normal distribution, i.e., $\lambda_{i} \sim N\left(\lambda_{0}, \Lambda_{0}\right)$ with $\lambda_{0}=1$ and $\Lambda_{0}=25$, as in Pitt and Shephard (1999). The choice of relatively large $\Lambda_{0}$ represents a fair degree of uncertainty around the factor loadings. The initial value of the factor loadings is the OLS estimates of forecasting errors on the first principal component as a proxy of a factor. Since the factor and loadings are not completely identified in a factor model, we set the loading of the first variable (i.e., GDP) to be equal to one, a commonly used identification strategy of a factor model. Factor loadings of the second to the last variable are drawn from the posterior distribution introduced below.

A diffuse Normal prior is used as the prior distribution for a factor conditional on $\left\{h_{f, t}\right\}_{t=1}^{T}$, consistent with (3) (i.e., $f_{t} \sim N\left(\theta_{0}, \Theta_{0}\right)$ where $\theta_{0}=0$ and $\Theta_{0}=h_{f, t}$ ). As mentioned above, we use the first principal component for the initial iteration.

The prior for the variability of volatilities is the inverse Gamma, i.e., $\sigma_{f}^{2}$ and $\sigma_{i}^{2}$ $\sim I G\left(\frac{v_{0}}{2}, \frac{\delta_{0}}{2}\right)$. We set $v_{0}=1$ and $\delta_{0}=1$, which makes the conditional prior distribution flatter than that in Pitt and Shephard (1999) and more so than those in other recent studies incorporating stochastic volatility (see, e.g., Primiceri 2005; Baumeister et al. 2013) to allow for a large time variation for stochastic volatilities a priori. Compared with the above recent studies, the total number of parameters to estimate is substantially smaller in our case. Thus, we use a more diffuse prior and put a larger weight on data.

The prior of each time-varying volatility is the log-Normal. In particular, for the initial period's stochastic volatility, $h_{0}^{2}$, we have $\log h_{0} \sim N\left(\mu_{0}^{h}, V_{0}^{h}\right)$, where $\mu_{0}^{h}=1$ and $V_{0}^{h}=10$ to allow a good chance for the data to determine the posterior distribution. 


\section{A.2 Posterior Distribution Simulation}

The MCMC algorithm for the estimation of the joint posterior distribution of an FSV model closely follows the one introduced in Pitt and Shephard (1999). We divide the parameters in the model into four blocks: (a) the factor loadings $(\lambda)$; (b) the time series of the factor $\left(\left\{f_{t}\right\}_{t=1}^{T}\right)$; (c) the hyperparameters for volatilities $\left(\sigma_{f}\right.$; and $\sigma_{i}$ for all $i$ ); and (d) the volatility states $\left(\left\{h_{f, t}\right\}_{t=1}^{T}\right.$ and $\left\{h_{i, t}\right\}_{t=1}^{T}$ for all $i$ ). Due to the conditional independence across $t$ and $i$ as well as of $f_{t}$ and $u_{i, t}$ 's, most steps in the Gibbs sampler, such as drawing factor loadings $(\{\lambda\})$, volatility states $(\{h\})$ and the variance of volatilities $(\{\sigma\})$ further break down to drawing from a univariate process. Finally, the volatility states are drawn via Metropolis methods within the overall Gibbs sampler. Denoting by $z^{T}$ the time series of a variable $z$ from $t=1$ to $T$, the sampler algorithm is described below.

\section{A.2.1 Factor loadings}

Conditional on all other parameters, this step becomes a simple Bayesian regression of forecasting errors on the factor with known heteroskedastic error structures. Moreover, because all correlations are by definition captured by the factor, this step further decomposes into the $n$ sub-steps of drawing each $i$-th loading separately from the following distribution, given the history of variable $i$ :

$$
\lambda_{i} \mid \varepsilon^{T}, f^{T}, \sigma_{f}, \sigma_{i}, h_{f}^{T}, h_{i}^{T} \sim N\left(\lambda_{1}, \Lambda_{1}\right)
$$

where $\Lambda_{1}=\left(\Lambda_{0}^{-1}+\sum_{t=1}^{T} f_{t}^{2} /\left(h_{i, t}\right)\right)^{-1}$ and $\lambda_{1}=\Lambda_{1}\left(\Lambda_{0}^{-1} \lambda_{0}+\sum_{t=1}^{T} f_{t} \cdot \varepsilon_{i, t} /\left(h_{i, t}\right)\right)$ with $s \geq 1$ as the starting point of each forecasting error series $\varepsilon_{i}$.

\section{A.2.2 Factor}

Conditional independence also simplifies this step. Given all other parameter values, this step again becomes a Bayesian regression of available forecasting errors on factor loadings with known heteroskedasticity for each period $t$. That is,

$$
f_{t} \mid \varepsilon^{T}, \lambda_{i}, \sigma_{f}, \sigma_{i}, h_{f}^{T}, h_{i}^{T} \sim N\left(\theta_{1}, \Theta_{1}\right)
$$


where $\Theta_{1}=\left\{h_{f, t}^{-1}+\sum_{i=1}^{n} \lambda_{i}^{2}\left(h_{i, t}\right)\right\}^{-1}$, and $\theta_{1}=\Theta_{1}\left(\sum_{i=1}^{n} \lambda_{i} \cdot \varepsilon_{i, t} /\left(h_{f, t}\right)\right)$.

\section{A.2.3 Innovation variance of volatilities}

Since we model each stochastic volatility to follow a unit-root process without a drift, the conditional posterior distribution of $\sigma$ can be simplified from the posterior inverse Gamma distribution in Kim et al. (1998). Hence, $\sigma^{2}$ is drawn from

$$
\sigma \mid \varepsilon^{T}, f^{T}, h_{f}^{T}, h_{i}^{T} \sim I G\left(\frac{v_{1}}{2}, \frac{\delta_{1}}{2}\right)
$$

where $v_{1}=v_{0}+T$, and $\delta_{1}=\delta_{0}+\sum_{t=1}^{T}\left(h_{i, t}-h_{i, t-1}\right)^{2}$.

\section{A.2.4 Volatility states}

This step further decomposes to the $n+1$ sub-steps of univariate stochastic volatility draws, based on the Markovian property of stochastic volatility. It follows the algorithm by Jacquier et al. (2002) as used in Cogley and Sargent (2005). For each volatility series of an idiosyncratic error $i$ or of the factor, the algorithm draws the exponential of volatility $\left(h_{i, t}^{2}\right)$ one by one for each $t=1, \ldots, T$, based on $f\left(h_{i, t} \mid h_{i, t-1}, h_{i, t+1}, y_{i}^{T}, \lambda, f^{T}, \sigma\right)$.

Before sampling the states, we first transform forecasting errors to be $\varepsilon_{i, t}^{*}=\varepsilon_{i, t}-\lambda_{i, t} f_{t}$. Such transformation is unnecessary for the factor. Then, we apply the Jacquier et al. (2002) algorithm for each date, i.e.,

$$
\begin{aligned}
f\left(h_{i, t} \mid\left(h_{i}\right)_{-t}^{T}, y_{i}^{* T}, \sigma\right) & =f\left(h_{i, t} \mid h_{i, t-1}, h_{i, t+1}, y_{i}^{* T}, \sigma\right) \\
& \propto f\left(y_{i, t}^{*} \mid h_{i, t}\right) f\left(h_{i, t} \mid h_{i, t-1}\right) f\left(h_{i, t+1} \mid h_{i, t}\right) \\
& =\left(h_{i, t}\right)^{-1.5} \exp \left(\frac{-y_{i, t}^{*}}{2 h_{i, t}}\right) \exp \left(\frac{-\left(\log h_{i, t}-\mu_{t}\right)^{2}}{2 \sigma_{c}^{2}}\right),
\end{aligned}
$$

where $\mu_{t}$ and $\sigma_{c}^{2}$ are the conditional mean and variance of $\log h_{i, t}$, respectively. Under the unit-root specification of this paper, they can be calculated as

$$
\begin{aligned}
\mu_{t} & =\frac{\left(\log h_{i, t-1}+\log h_{i, t+1}\right)}{2}, \\
\sigma_{c}^{2} & =\frac{\sigma_{i}^{2}}{2}
\end{aligned}
$$


for $t=1, \cdots, T-1$. Thus, a trial value of $\log h_{i, t}$ is drawn from the Normal distribution with mean $\mu_{t}$ and variance $\sigma_{c}^{2}$. For the beginning and end periods of each series $i$, the following conditional mean and variance are used instead:

$$
\begin{array}{lll}
t=0: & \sigma_{c}^{2}=\frac{\sigma_{i} V_{0}^{h}}{\sigma_{i}+V_{0}^{h}}, & \mu=\sigma_{c}^{2}\left(\frac{\mu_{0}^{h}}{V_{0}^{h}}+\frac{\log h_{i, t+1}}{\sigma_{i}^{2}}\right), \\
t=T: & \sigma_{c}^{2}=\sigma_{i}^{2}, & \mu=\log h_{i, T-1} .
\end{array}
$$

After obtaining a draw, the conditional likelihood $f\left(y_{i, t}^{*} \mid h_{i, t}\right)$ is evaluated in order to obtain the acceptance probability, completing a Metropolis step (see Cogley and Sargent 2005 for a detailed description).

We can summarize the estimation procedure as following:

1. Assign initial values for $\lambda, f^{T}, \sigma_{f}, \sigma_{i}$ for all $i, h_{f}^{T}$, and $h_{i}^{T}$ for all $i$.

2. Draw $\lambda$ from $p\left(\lambda \mid \varepsilon^{T}, f^{T}, \sigma_{f}, \sigma_{i}, h_{f}^{T}, h_{i}^{T}\right)$.

3. Draw $f^{T}$ from $p\left(f^{T} \mid \varepsilon^{T}, \lambda, \sigma_{f}, \sigma_{i}, h_{f}^{T}, h_{i}^{T}\right)$.

4. Draw $\sigma_{f}$ and $\sigma_{i}$ s from $p\left(\sigma \mid \varepsilon^{T}, f^{T}, h_{f}^{T}, h_{i}^{T}\right)$.

5. Draw $h_{f}^{T}$, and $h_{i}^{T}$ s from $p\left(h \mid \varepsilon^{T}, f^{T}, \sigma_{f}, \sigma_{i}\right)$.

6. Go to step 2.

We iterate over the Metropolis-within-Gibbs sampler a total of 80,000 times, discarding the first 30,000 draws of parameters. Then we store every 10th draw in order to avoid potential autocorrelation across draws, and finally obtain 5,000 draws from the joint posterior distribution.

\section{References}

Aastveit, K. A., G. J. Natvik, And S. Sola (2013): "Economic Uncertainty and the Effectiveness of Monetary Policy," Norges Bank Working Paper Series, 17.

Aguilar, O. And M. West (2000): "Bayesian dynamic factor models and portfolio allocation," Journal of Business \& Economic Statistics, 18, 338-357.

Aiolfi, M., C. Capistran, And A. Timmermann (2011): "Forecast Combinations," 
in The Oxford Handbook of Economic Forecasting, ed. by M. Clements and D. Hendry, Oxford University Press, 355-88.

Alexopoulos, M. And J. Cohen (2009): "Uncertain Times, Uncertain Measures," University of Toronto Department of Economics Working Paper, 352.

Amato, J. D. And N. R. Swanson (2001): "The real-time predictive content of money for output," Journal of Monetary Economics, 48, 3-24.

Amir Ahmadi, P., C. Matthes, and M.-C. Wang (2015): "Measurement Errors and Monetary Policy: Then and Now," FRB Richmond Working Paper, 15-84.

Ang, A., G. Bekaert, And M. Wei (2007): "Do Macro Variables, Asset Markets, or Surveys Forecast Inflation Better?" Journal of Monetary Economics, 54, 1163-1212.

ArAI, N. (2014): "Using forecast evaluation to improve the accuracy of the Greenbook forecast," International Journal of Forecasting, 30, 12-19.

Arellano, C., Y. Bai, And P. J. Kehoe (2012): "Financial Frictions and Fluctuations in Volatility," Federal Reserve Bank of Minneapolis Research Department Staff Report, 466.

AruobA, S. B. (2008): "Data revisions are not well behaved," Journal of Money, Credit and Banking, 40, 319-340.

Bachmann, R., S. Elstner, And E. Sims (2013): "Uncertainty and Economic Activity: Evidence from Business Survey Data," American Economic Journal: Macroeconomics, $5,217-49$.

Baker, S. R., N. Bloom, And S. J. Davis (2013): "Measuring Economic Policy Uncertainty," Chicago Booth Research Paper, 13-02.

Baumeister, C., P. Liu, And H. Mumtaz (2013): "Changes in the Effects of Monetary Policy on Disaggregate Price Dynamics," Journal of Economic Dynamics and Control, $37,543-560$.

Bekaert, G., M. Hoerova, And M. L. Duca (2013): "Risk, uncertainty and monetary policy," Journal of Monetary Economics, 60, 771-788.

Bloom, N. (2009): "The Impact of Uncertainty Shocks," Econometrica, 77, 623-685.

Bloom, N., M. Floetotto, N. Jaimovich, I. Saporta-Eksten, and S. J. Terry (2012): "Really Uncertain Business Cycles," NBER Working Paper, w18245.

Caggiano, G., E. Castelnuovo, and N. Groshenny (2014): "Uncertainty Shocks and Unemployment Dynamics: An Analysis of Post-WWII US Recessions," Journal of Monetary Economics, 67, 78-92. 
Caldara, D., J. Fernandez-Villaverde, J. F. Rubio-Ramirez, and W. Yao (2012): "Computing DSGE models with recursive preferences and stochastic volatility," Review of Economic Dynamics, 15, 188-206.

Carriero, A., T. E. Clark, and M. Marcellino (2015): "Common drifting volatility in large Bayesian VARs," Journal of Business 83 Economic Statistics, forthcoming.

Chib, S., F. Nardari, and N. Shephard (2006): "Analysis of high dimensional multivariate stochastic volatility models," Journal of Econometrics, 134, 341-371.

Chib, S., Y. OMori, AND M. Asai (2009): "Multivariate stochastic volatility," in Handbook of Financial Time Series, Springer, 365-400.

Cogley, T. and T. J. Sargent (2005): "Drifts and Volatilities: Monetary Policies and Outcomes in the Post-WWII U.S." Review of Economic Dynamics, 8, 262-302.

Collin-Dufresne, P. And R. S. Goldstein (2002): "Do bonds span the fixed income markets? Theory and evidence for unspanned stochastic volatility," The Journal of Finance, 57, 1685-1730.

Del Negro, M. and C. Otrok (2008): "Dynamic factor models with time-varying parameters: measuring changes in international business cycles," FRB of New York Staff Report.

Diebold, F. X. And G. D. Rudebusch (1991): "Forecasting output with the composite leading index: A real-time analysis," Journal of the American Statistical Association, 86, 603-610.

Faust, J., J. H. Rogers, And J. H. Wright (2003): "Exchange rate forecasting: the errors we've really made," Journal of International Economics, 60, 35-59.

(2005): "News and noise in G-7 GDP announcements," Journal of Money, Credit and Banking, 37, 403-419.

Faust, J. AND J. H. Wright (2013): "Forecasting Inflation," in Handbook of Economic Forecasting, ed. by G. Elliott and A. Timmermann, Elsevier, vol. 2, Part A of Handbook of Economic Forecasting, 2-56.

Ghysels, E., C. Horan, And E. Moench (2014): "Forecasting through the rear-view mirror: Data revisions and bond return predictability," FRB of New York Staff Report.

Heston, S. L. (1993): "A closed-form solution for options with stochastic volatility with applications to bond and currency options," Review of Financial Studies, 6, 327-343.

Jacquier, E., N. G. Polson, And P. E. Rossi (2002): "Bayesian Analysis of Stochastic Volatility Models," Journal of Business \&3 Economic Statistics, 20, 69-87.

Jo, S. (2014): "The Effects of Oil Price Uncertainty on Global Real Economic Activity," Journal of Money, Credit and Banking, 46, 1113-1135. 
JORDÀ, Ò. (2005): "Estimation and inference of impulse responses by local projections," American Economic Review, 95, 161-182.

Jurado, K., S. C. Ludvigson, And S. NG (2015): "Measuring Uncertainty," American Economic Review, 105, 1177-1216.

Justiniano, A. And G. E. Primiceri (2008): "The Time-Varying Volatility of Macroeconomic Fluctuations," American Economic Review, 98, 604.

Kastner, G., S. Frühwirth-Schnatter, And H. F. Lopes (2014): "Analysis of Exchange Rates via Multivariate Bayesian Factor Stochastic Volatility Models," in The Contribution of Young Researchers to Bayesian Statistics, Springer, 181-185.

Kilian, L. (1998): "Small-Sample Confidence Intervals for Impulse Response Functions," Review of Economics and Statistics, 80, 218-230.

Kim, C.-J. And C. R. Nelson (1999): "Has the US Economy Become More Stable? A Bayesian Approach Based on a Markov-Switching Model of the Business Cycle," Review of Economics and Statistics, 81, 608-616.

Kim, S., N. Shephard, And S. Chib (1998): "Stochastic Volatility: Likelihood Inference and Comparison with ARCH Models," Review of Economic Studies, 65, 361-393.

Lahiri, K. And X. Sheng (2010): "Measuring Forecast Uncertainty By Disagreement: The Missing Ink," Journal of Applied Econometrics, 25, 514-538.

Mankiw, N. G., R. Reis, And J. Wolfers (2004): "Disagreement About Inflation Expectations," in NBER Macroeconomics Annual 2003, Volume 18, The MIT Press, 209-270.

McConnell, M. M. And G. Perez-Quiros (2000): "Output Fluctuations in the United States: What Has Changed since the Early 1980's?" American Economic Review, 90, 1464-1476.

Mumtaz, H. And P. Surico (2013): "Policy Uncertainty and Aggregate Fluctuations," Working Paper, School of Economics and Finance, Queen Mary, University of London.

Mumtaz, H. And K. Theodoridis (2015): "Common and country specific economic uncertainty," Working Paper, School of Economics and Finance, Queen Mary, University of London.

Mumtaz, H. And F. Zanetti (2013): "The impact of the volatility of monetary policy shocks," Journal of Money, Credit and Banking, 45, 535-558.

Orphanides, A. (2001): "Monetary policy rules based on real-time data," American Economic Review, 91, 964-985.

Orphanides, A. And S. VAn Norden (2002): "The unreliability of output-gap estimates in real time," Review of Economics and Statistics, 84, 569-583. 
Pitt, M. And N. Shephard (1999): "Time-Varying Covariances: A Factor Stochastic Volatility Approach," Bayesian Statistics, 6, 547-570.

Primiceri, G. E. (2005): "Time varying structural vector autoregressions and monetary policy," Review of Economic Studies, 72, 821-852.

Rossi, B. And T. Sekhposyan (2015): "Macroeconomic uncertainty indices based on nowcast and forecast error distributions," American Economic Review, 105, 650-655.

Scotti, C. (2013): "Surprise and Uncertainty Indexes: Real-Time Aggregation of RealActivity Macro Surprises," FRB International Finance Discussion Paper, 1093.

SILL, K. (2012): "Measuring Economic Uncertainty Using the Survey of Professional Forecasters," Federal Reserve Bank of Philadelphia Business Review, 4, 16-27.

Stark, T. (2010): "Realistic Evaluation of Real-Time Forecasts in the Survey of Professional Forecasters," Federal Reserve Bank of Philadelphia Special Report.

Zarnowitz, V. And P. Braun (1993): "Twenty-two years of the NBER-ASA quarterly economic outlook surveys: Aspects and comparisons of forecasting performance," in Business cycles, indicators and forecasting, University of Chicago Press, 11-94. 